\title{
Bronchodilator tolerance: the impact of increasing bronchoconstriction
}

\author{
J.M. Wraight*, R.J. Hancox*, G.P. Herbison", J.O. Cowan*, E.M. Flannery*, D.R. Taylor*
}

Bronchodilator tolerance: the impact of increasing bronchoconstriction. J.M. Wraight, R.J. Hancox, G.P. Herbison, J.O. Cowan, E.M. Flannery, D.R. Taylor. (C) ER Journals Ltd 2003.

ABSTRACT: Chronic exposure to $\beta$-agonists causes tolerance to their bronchodilator effects, which is best demonstrated during acute bronchoconstriction. The aim of the present study was to assess whether tolerance becomes more evident with increasing bronchoconstriction, as might occur in acute asthma.

In a randomised, double-blind, placebo-controlled, crossover study comprising 15 patients, the treatments were salbutamol $400 \mu \mathrm{g}$ q.i.d. or placebo given via Diskhaler $\mathbb{R}$ for 28 days with a 2-week washout between treatments. Patients attended on days 14, 21 and 28. Bronchoconstriction was induced on two of these three occasions to achieve a reduction in the forced expiratory volume in one second (FEV1) of 0 (no methacholine), 15 and $30 \%$ (using methacholine) in a randomised order. Immediately after this, salbutamol $100 \mu \mathrm{g}, 100 \mu \mathrm{g}$ and $200 \mu \mathrm{g}$ was inhaled at 0,5 , and $10 \mathrm{~min}$. FEV1 was measured over $40 \mathrm{~min}$. Dose/response curves were plotted and values for the area under the curve (AUC)0-40 FEV1 were compared between treatments and by degree of bronchoconstriction.

Regular salbutamol resulted in attenuation of the acute response to $\beta$-agonist, which was increasingly evident with greater bronchoconstriction. With a reduction in FEV1 of 0,15 and 30\%, the AUC0-40 FEV1 with salbutamol were 11.2, -14.6 and -35.7\% respectively, compared to placebo. There was a linear relationship between the magnitude of bronchoconstriction and the between-treatment differences in AUC0-40 FEV1.

Increasing bronchoconstriction conferred greater susceptibility to the effects of bronchodilator tolerance.

Eur Respir J 2003; 21: 810-815.
Depts of *Medical and Surgical Sciences and ${ }^{\#}$ Preventive and Social Medicine, Dunedin School of Medicine, University of Otago, Dunedin, New Zealand.

Correspondence: D.R. Taylor, Dunedin School of Medicine, P.O. Box 913, Dunedin, New Zealand.

Fax: 6434747641

E-mail: robin.taylor@stonebow.otago. ac.nz

Keywords: Asthma

$\beta$-agonist

tachyphylaxis

tolerance

salbutamol

Received: July 262002

Accepted after revision: January 42003

This study was supported by the Asthma and Respiratory Foundation of New Zealand. J.M. Wraight was a GlaxoSmithKline research fellow. $\beta$-agonists are widely prescribed for symptomatic relief in asthma. They are very effective as bronchodilators and as functional antagonists against a wide range of constricting stimuli. However, chronic exposure of $\beta$-adrenoceptors ( $\beta$-AR) to $\beta$-agonist drugs leads to reduced responsiveness (desensitisation) and a decrease in the number of receptors (downregulation) [1].

In the clinical setting, tolerance to the nonbronchodilator effects of $\beta$-agonists is readily demonstrated [2, 3]. However, it has been more difficult to demonstrate tolerance to their bronchodilator effects. Reduced bronchodilator response after regular short- and long-acting $\beta$-agonists has been reported [4-7] but the findings have been inconsistent [8-11]. A possible explanation for these negative results is that bronchodilator responses were measured in patients with stable asthma in whom the margin from baseline to maximum bronchodilatation was not sufficient for the effects of tolerance to be detected.

Recently, HANCOX et al. [12] have described a method that reliably demonstrates bronchodilator tolerance to $\beta$-agonists. In that study, a $36 \%$ reduction in the area under the curve (AUC) for forced expiratory volume (FEV1) was observed in patients who had been using regular inhaled $\beta$-agonist compared to placebo. Subsequently, other authors have used the same methodology to show similar effects in patients using long-acting $\beta$-agonists $[13,14]$. In both of these studies, measuring the response to $\beta$-agonist in the presence of methacholineinduced bronchoconstriction permitted the demonstration of tolerance which would not otherwise have been detected.
These findings raise the possibility that the effects of tolerance to inhaled $\beta$-agonists may be further accentuated by bronchoconstriction beyond the $20 \%$ fall in FEV1 that was induced in these investigations [12-14]. In acute severe asthma, patients will usually have a reduction in their FEV1 that greatly exceeds $20 \%$. $\beta$-agonists are firstline treatment for acute episodes of asthma and the clinical impact of bronchodilator tolerance will be most important in this setting. The aim of this study was to assess whether a relationship exists between the severity of bronchoconstriction and the impact of tolerance to the acute bronchodilator effect of $\beta$-agonists.

\section{Methods}

\section{Study subjects}

Volunteers aged 18-70 yrs were screened for airways reversibility and for response to methacholine. The inclusion criteria were: a diagnosis of bronchial asthma that met the American Thoracic Society (ATS) definition [15]; a provocative dose of methacholine causing a $20 \%$ fall in FEV1 (PD20) of $<8 \mu \mathrm{mol}[16]$; an increase in FEV1 of $>15 \%$ from baseline with inhaled salbutamol; nonsmokers or exsmokers $(<5$ pack-yrs). Subjects were excluded if they: had a history of life-threatening asthma; a recent respiratory tract infection (6 weeks); had recent unstable asthma or needed oral steroids 
Table 1.-Baseline data for patients who were randomised to study treatments
Subjects n (F)

FEV1 L

FEV1 \% pred

Mean daily ICS dose (range) $\mu \mathrm{g}$

Reversibility after salbutamol ${ }^{\#} \%$
PD20 methacholine $\mu \mathrm{mol}^{\oplus}$
$15(9)$

$2.06(1.68-2.43)$

$75.3(66.6-84.0)$

$640(0-1000)$

$25.7(20.2-31.2)$

$0.32(0.21-0.50)$
Data are presented as mean ( $95 \%$ confidence intervals), unless otherwise stated. F: females; FEV1: forced expiratory volume in one second; $\%$ pred: $\%$ predicted; ICS: inhaled corticosteroid. ${ }^{\#}$ : $\triangle F E V 1$ as $\%$ of baseline; ${ }^{\top}$ : the provocative dose of methacholine causing a $20 \%$ fall in the FEV1 (PD20) is given as geometric mean.

in the past 3 months; were dependent on short- or long-acting $\beta$-agonists; or were pregnant or breastfeeding. Baseline characteristics for the subjects who completed the study are shown in table 1 .

\section{Study design}

Subjects initially entered a 2 -week run-in period during which inhaled $\beta$-agonists were withdrawn and baseline peakflow measurements and symptom data were recorded. The only "reliever" medication allowed was ipratropium bromide (Atrovent $\mathbb{R}$; Boehringer, Ingelheim, Germany) for use as required. Subjects were withdrawn from the study if they could not tolerate or obtain adequate symptom relief using ipratropium bromide, or had unstable asthma during these 2 weeks. Diary data from the run-in was used to construct individual asthma self-management plans for use during the remainder of the study.

Subjects then received two study treatments according to a randomised, double-blind, placebo-controlled, crossover design. The treatment periods lasted 4 weeks each and were separated by a 2-week washout. The study medications were salbutamol $400 \mu \mathrm{g}$ q.i.d via Diskhaler $\mathbb{R}$ (Ventolin $\mathbb{R}$; GlaxoWellcome, Greenford, UK) or matching placebo. Subjects were randomised according to a schedule generated by the Dunedin Hospital Pharmacy (Dunedin, New Zealand).

\section{Study visits and measurements}

Subjects visited the research laboratory on days $14 \pm 2$, $21 \pm 2$ and $28 \pm 2$ of each treatment period. Study medication and ipratropium bromide were withheld for $\geqslant 6 \mathrm{~h}$ prior to each visit. On two of the three visits a methacholine challenge was performed in order to achieve bronchoconstriction. A fall in FEV1 of $15 \%$ was induced on one occasion and $30 \%$ on another. On a third occasion no methacholine challenge was undertaken. The order of the three tests was randomised, but was identical during the second treatment arm. The bronchodilator response to salbutamol was performed following methacholine challenge.

\section{Methacholine challenge}

A modified procedure [16] was used in which increasing doses of methacholine were administered using a Morgan Nebicheck $\mathbb{R}$ Dosimeter (Morgan, Gillingham, UK). The procedure was stopped when the required fall of $15 \%$ (PD15 group) or $30 \%$ (PD30 group) in FEV1 from baseline was achieved. The PD of methacholine was calculated by linear interpolation. Methacholine was not administered if the prechallenge FEV1 was $<1 \mathrm{~L}$. Although a fall in FEV1 of $30 \%$ was greater than would normally be induced during a methacholine challenge, it was less than would be expected during an acute exacerbation of asthma and was considered appropriate in order to test the study hypothesis. The challenges were all performed under medical supervision and in a laboratory that had ready access to full resuscitation facilities.

\section{Bronchodilator response}

Immediately after the required fall in FEV1 was achieved, a dose/response test to inhaled salbutamol (GlaxoWellcome) was performed. Salbutamol was administered at 0,5 and 10 min via a metered-dose inhaler and large-volume spacer device (GlaxoWellcome). The doses were $100 \mu \mathrm{g}, 100 \mu \mathrm{g}$ and $200 \mu \mathrm{g}$ respectively. FEV1 was measured prior to each dose and also at 15, 25 and $40 \mathrm{~min}$. A dose/response curve was plotted for FEV1 against time (0-40 min). In cases where adequate reversal of bronchconstriction was not achieved using these doses, additional salbutamol was administered by nebuliser $(2.5 \mathrm{mg})$. Patients remained in the research laboratory until baseline FEV1 had been recovered.

\section{Sample size and statistical analysis}

The sample-size calculation was based on the results of two previous studies [12, 14], although in these studies, differences in AUC0-40 FEV1 followed a 20\% fall in FEV1 (rather than the 15 and $30 \%$ in this study). The primary study end-point was AUC (AUC0-40 FEV1) for change in FEV1 over 40 min following inhaled salbutamol. Differences between treatments and by magnitude of bronchoconstriction were measured by analysis of covariance using baseline FEV1, PD of methacholine and fall in FEV1 from baseline as covariates. Curves were also constructed that compared changes in AUC0-40 FEV1 to magnitude of bronchconstriction, and their slopes were then compared between treatments. All results are presented as least squares means with Bonferroni corrections.

\section{Ethical considerations}

The study was approved by the Otago Ethics Committee. Each subject gave written informed consent. Asthma control was monitored throughout the study and individual asthma self-management plans were given to each patient. Patients had access to a study investigator $24 \mathrm{~h} \cdot \mathrm{day}^{-1}$.

\section{Results}

\section{Subjects}

Twenty-one subjects were randomised, of whom 15 completed both treatment arms. Reasons for withdrawal are shown in table 2 . Only patients who completed both arms of the study were included in the analysis. One patient was excluded from having a PD30 methacholine challenge because the baseline FEV1 was $<1$ L. No patient experienced significant adverse events following methacholine apart from mild wheeze. Adherence to study medication, measured by returned disk count, was $90 \%$ in the first arm and $95 \%$ in the second arm. 
Table 2. - Reasons for withdrawal during run-in

Reason Subjects $n$

Exacerbation of asthma

Poor compliance

Drug reaction

Used $\beta$-agonist inappropriately

1

Changes in forced expiratory volume in one second before and after methacholine

Baseline FEV1 and per cent fall in FEV1 after methacholine are shown in table 3. Compared to placebo, the baseline FEV1 prior to methacholine administration was reduced by $0.23 \mathrm{~L}(\mathrm{p}=0.04), 0.14 \mathrm{~L}(\mathrm{p}=0.2)$ and $0.18 \mathrm{~L}(\mathrm{p}=0.002)$ with regular salbutamol on each of the three study days respectively.

\section{Relationship between tolerance and magnitude of bronchoconstriction}

The AUC0-40 (FEV1) values are shown in table 4 and figure 1 . There was a highly significant reduction $(35.7 \%)$ in the AUC0-40 FEV1 with active treatment when the target fall in FEV1 was 30\% $(\mathrm{p}=0.0001)$ but not when the target fall in FEV1 was 0 or $15 \%$. Whereas with placebo treatment the AUC0-40 FEV1 tended to increase with greater magnitudes of bronchoconstriction, the opposite effect occurred with regular salbutamol. Curves were constructed to evaluate the relative changes in AUC0-40 FEV1 with increasing bronchoconstriction (fig. 1). There was a highly significant difference between the slopes of the curves $(\mathrm{p}=0.0001)$.

\section{Doselresponse curves to salbutamol after methacholine}

Dose/response curves to salbutamol are shown in figure 2. The FEV1 achieved at $40 \mathrm{~min}$ (of three measurements on

separate days) was lower in each of the salbutamol arms compared to placebo. This was most marked with the target fall in FEV1 of $30 \%$, where the difference compared to placebo was $-0.27 \mathrm{~L}(\mathrm{p}=0.0001)$.

\section{Discussion}

The results of this study show that in subjects with mild-tomoderate asthma, continuous use of inhaled $\beta$-agonist causes an attenuated bronchodilator response to acutely administered $\beta$-agonist. Compared to pre-treatment with placebo, there was a highly significant near-linear reduction in AUC0-40 FEV1 with $\beta$-agonist as bronchoconstriction increased $(\mathrm{p}<0.0001)$. Thus, the present study goes further than earlier investigations [12-14] by demonstrating that, in the same patient, the effects of pharmacological tolerance become increasingly apparent with increasing degrees of bronchoconstriction.

Although challenge with methacholine is an artificial means of inducing bronchconstriction, the findings may have clinical implications for the treatment of acute severe asthma. Most patients attending an emergency department with acute asthma will have used large amounts of $\beta$-agonist medications before presentation and will have bronchoconstriction that is even more severe than that induced in this study. Furthermore, there is evidence that with increasing airway inflammation, $\beta$-AR become hyporesponsive, thus potentially compounding the effects of pharmacologically mediated downregulation [17]. The present results suggest that the effects of $\beta$-agonist tolerance in such patients may be accentuated and result in resistance to acutely administered $\beta$-agonist therapy. Indirect evidence to support this has been obtained from studies that describe the benefit of combined salbutamol/ipratropium compared to salbutamol alone in acute asthma [18-20]. These investigations showed that the increase in FEV1 with combination therapy was most marked in patients with the most severe asthma at presentation. It may be that this observation was due to "resistance" to the bronchodilator effects of acutely

Table 3.-Changes in the forced expiratory volume in one second (FEV 1 ) before and after methacholine

\begin{tabular}{|c|c|c|c|c|c|c|c|c|}
\hline \multirow{2}{*}{$\begin{array}{l}\text { Target fall in } \\
\text { FEV1 } \%\end{array}$} & \multicolumn{3}{|c|}{ Pretreatment with placebo } & \multirow{2}{*}{$\begin{array}{c}\mathrm{PD} \\
(\mu \mathrm{mol})\end{array}$} & \multicolumn{3}{|c|}{ Pretreatment with regular salbutamol } & \multirow{2}{*}{$\begin{array}{c}\text { PD } \\
(\mu \mathrm{mol})\end{array}$} \\
\hline & $\begin{array}{l}\text { Before } \\
\text { MCh }\end{array}$ & $\begin{array}{l}\text { After } \\
\text { MCh }\end{array}$ & $\%$ change & & $\begin{array}{l}\text { Before } \\
\text { MCh }\end{array}$ & $\begin{array}{l}\text { After } \\
\text { MCh }\end{array}$ & $\%$ change & \\
\hline 0 & $\begin{array}{c}2.19 \\
(1.75-2.62)\end{array}$ & NA & 0 & 0 & $\begin{array}{c}1.96 \\
(1.56-2.36)\end{array}$ & NA & 0 & 0 \\
\hline 15 & $\begin{array}{c}2.21 \\
(1.80-2.63)\end{array}$ & $\begin{array}{c}1.81 \\
(1.36-2.02)\end{array}$ & $\begin{array}{c}18.0 \\
(16.6-20.6)\end{array}$ & $\begin{array}{c}0.11 \\
(0.09-0.14)\end{array}$ & $\begin{array}{c}2.07 \\
(1.66-2.49)\end{array}$ & $\begin{array}{c}1.81 \\
(1.36-2.03)\end{array}$ & $\begin{array}{c}18.2 \\
(16.0-19.9)\end{array}$ & $\begin{array}{c}0.17 \\
(0.09-0.32)\end{array}$ \\
\hline 30 & $\begin{array}{c}2.27 \\
(1.87-2.67)\end{array}$ & $\begin{array}{c}1.49 \\
(1.22-1.75)\end{array}$ & $\begin{array}{c}34.6 \\
(32.2-36.5)\end{array}$ & $\begin{array}{c}0.71 \\
(0.57-0.87)\end{array}$ & $\begin{array}{c}2.09 \\
(1.70-2.49)\end{array}$ & $\begin{array}{c}1.48 \\
(1.11-1.67)\end{array}$ & $\begin{array}{c}33.6 \\
(32.1-36.0)\end{array}$ & $\begin{array}{c}0.72 \\
(0.34-1.53)\end{array}$ \\
\hline
\end{tabular}

Data are presented as mean (95\% confidence intervals). The provocative dose (PD) of methacholine is given as the geometric mean $(\mu \mathrm{mol})$. The target fall in the FEV1 was achieved on separate days in random order. MCh: methacholine; NA: not applicable.

Table 4. - Area under the curve (AUC0-40 forced expiratory volume in one second $\left(F E V_{1}\right)$ ) values for the postmethacholine changes in FEV 1 following salbutamol

\begin{tabular}{|c|c|c|c|c|}
\hline \multirow[t]{2}{*}{ Target fall in FEV1 $\%$} & \multicolumn{2}{|c|}{ AUC0-40 FEV1 } & \multirow[t]{2}{*}{ Difference $\%$} & \multirow[t]{2}{*}{ p-value } \\
\hline & Salbutamol & Placebo & & \\
\hline 0 & $30.25(22.76-37.74)$ & $27.20(19.58-34.82)$ & 11.2 & 1.0 \\
\hline 15 & $25.72(19.19-32.25)$ & $30.12(23.57-36.67)$ & -14.6 & 0.602 \\
\hline 30 & $20.37(12.80-27.94)$ & $30.66(23.90-38.42)$ & -35.7 & 0.0001 \\
\hline
\end{tabular}




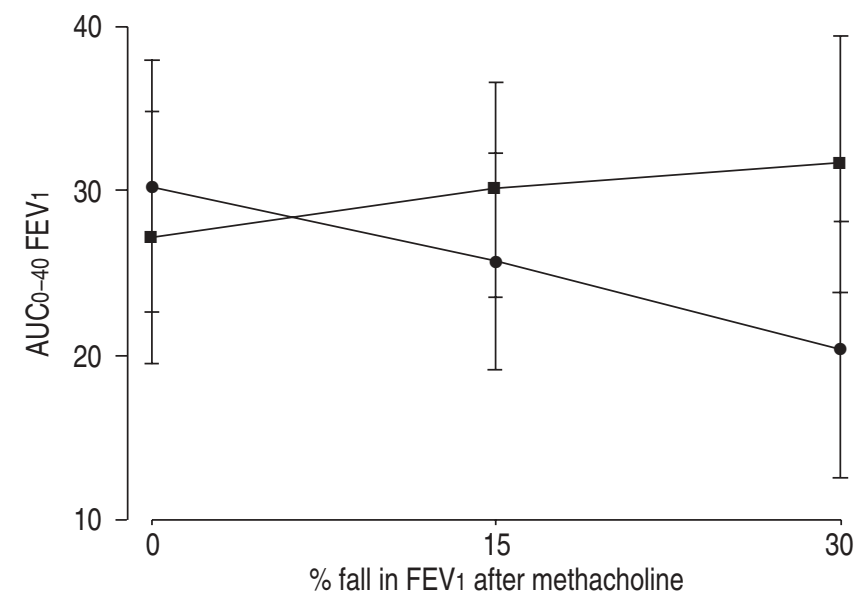

Fig. 1.-Relationship between changes in area under the curve (AUC) $0-40$ for the forced expiratory volume in one second (FEV 1 ) and degree of bronchoconstriction. There was a significant fall in AUC with regular salbutamol (@), but no change with placebo (ם).
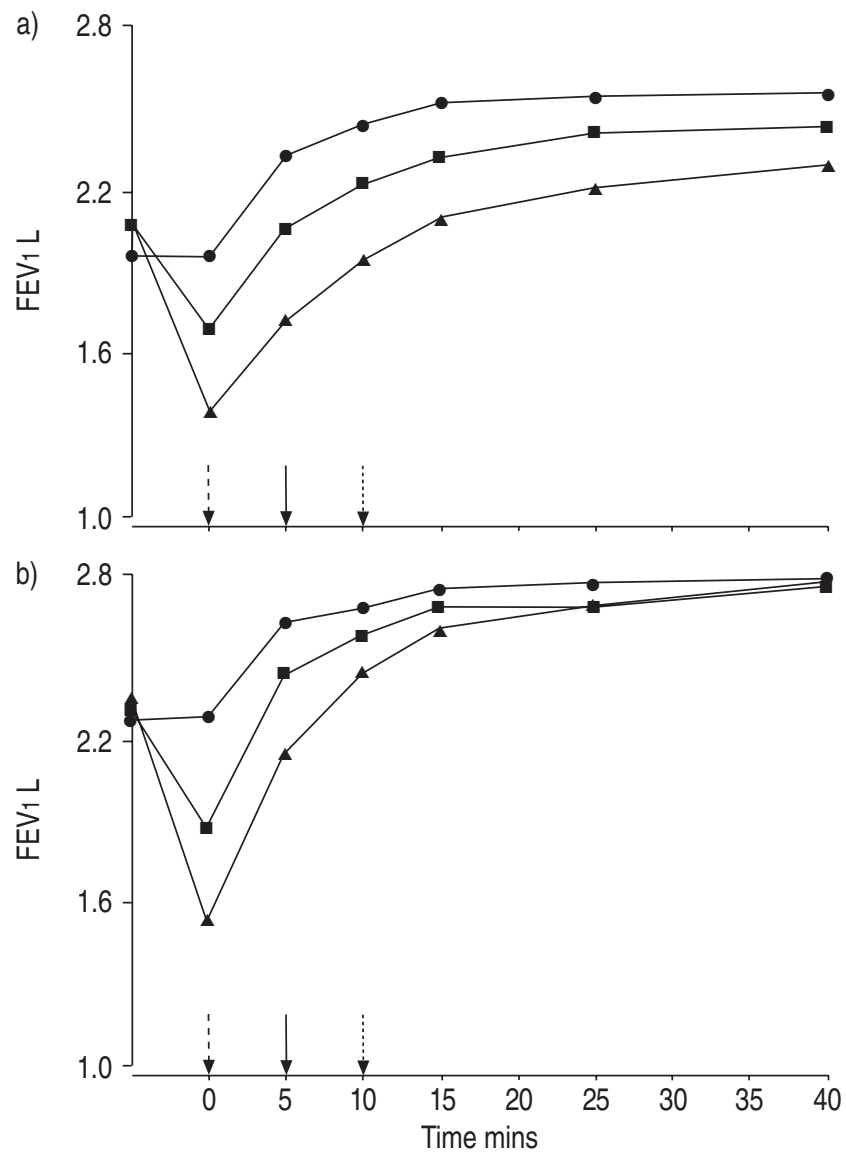

Fig. 2. - Mean changes in the forced expiratory volume in one second (FEV1) for pretreatment with a) salbutamol and b) placebo $(n=15)$ after administration of inhaled salbutamol $100 \mu \mathrm{g}$ (dashed arrow), $100 \mu \mathrm{g}$ (solid arrow) and $200 \mu \mathrm{g}$ (dotted arrow) with different degrees of bronchconstriction (target fall in FEV $10(\mathbf{O}), 15(\mathbf{a})$ and $30 \%$ $(\Delta))$ achieved using inhaled methacholine.

administered $\beta$-agonist rather than improved efficacy attributable to ipratropium bromide.

From figure 2, it can be seen that the response curves for FEV1 after acute salbutamol administration at the end of the placebo treatment period converged, whereas with regular
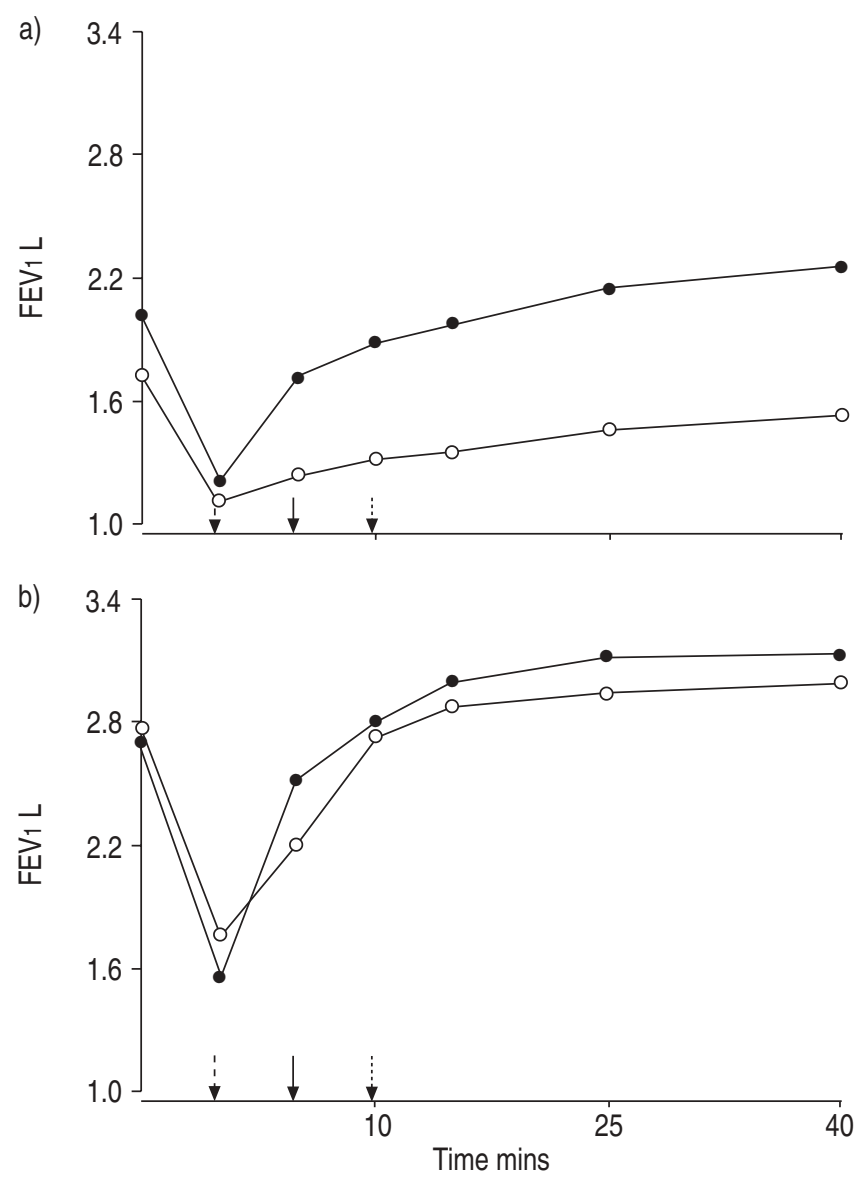

Fig. 3. - Bronchodilator response to salbutamol (inhaled salbutamol $100 \mu \mathrm{g}$ (dashed arrow), $100 \mu \mathrm{g}$ (solid arrow) and $200 \mu \mathrm{g}$ (dotted arrow)) in two individual patients after inducing a $30 \%$ fall in the forced expiratory volume in one second $\left(\mathrm{FEV}_{1}\right)$. In one patient, pretreatment with salbutamol conferred a) a significant degree of bronchodilator tolerance whereas in the other b) no significant tolerance occurred. $\bigcirc$ : salbutamol; $\bullet$ : placebo.

$\beta$-agonist they did not. This effect was seen most clearly when a $30 \%$ fall in FEV1 was induced. Even after an interval of $40 \mathrm{~min}$ following $400 \mu \mathrm{g}$ of salbutamol, by which time there would have been substantial spontaneous recovery from methacholine-induced bronchconstriction [12], bronchodilatation was less with salbutamol pretreatment than with placebo. The implication is that against a background of continuous inhaled salbutamol use, the acute response to $\beta$-agonist is submaximal in comparison to the patient's potential best. Significant heterogeneity was also observed in individual postbronchoconstriction bronchodilator responses. Some patients were highly resistant to acutely administered $\beta$-agonist at the end of the salbutamol treatment period, to the extent that recovery to baseline FEV1 could not be achieved after the methacholine challenge (30\% fall) (fig. 3). Perhaps such patients are most at risk during acute severe asthma [21, 22]. While the cumulative dose of salbutamol $(400 \mu \mathrm{g})$ used in this study appears to be small, it was administered via a large volume spacer in controlled laboratory conditions. The amount of drug delivered was probably higher than that achieved by some patients during an acute asthma episode. Although in emergency departments, the effects of tolerance may be overcome by using high doses of nebulised salbutamol [23], the appropriateness of this approach in an unattended setting is questionable.

There was also a significant trend towards lower baseline FEV1 measurements with regular salbutamol. Overall the 
mean difference was $-0.18 \mathrm{~L}(\mathrm{p}<0.0001)$. This has been noted in a number of previous studies [24-26] and it was for this reason that the baseline FEV1 on each study day was used as a covariate in the analysis of results. The exact mechanism for this reduction in airway calibre with short-acting $\beta_{2}$-agonists is unclear, but includes "rebound" bronchoconstriction as a result of downregulation of airway $\beta_{2}$-receptors. The bronchodilator response to $\beta_{2}$-agonist in human airways is primarily mediated by $\beta$-adrenoceptors on smooth muscle. There are also prejunctional $\beta$-receptors on postganglionic parasympathetic nerves which inhibit cholinergic transmission [27, 28]. The effects of stimulation of these receptors are the inhibition of parasympathetic control of bronchomotor tone and antagonisation of acute cholinergically mediated bronchoconstriction. Prejunctional $\beta$-receptors are likely to be desensitised and/or downregulated just as much as receptors on airway smooth muscle, and thus the decrease in baseline FEV1 may be due to decreased inhibition of cholinergic tone.

The results of this study were obtained in a setting of artificially induced bronchoconstriction, using inhaled methacholine. Although designed to mimic an acute asthma episode, there are important differences. In reality, exacerbations of asthma are characterised by airway inflammation causing mucosal oedema and mucus hypersecretion in addition to smooth muscle contraction. Thus, during acute severe asthma, there are likely to be additional interactions between pharmacological, physiological and physical factors not accounted for in the study model, which impair bronchodilator response. Nevertheless, $\beta$-agonists are used in acute asthma for their relaxing effect on airway smooth muscle, and this is what has been tested in this study. Further, in a recent study, similar suboptimal responses to $\beta$-agonist were observed using exercise rather than methacholine to induce bronchoconstriction, arguably a less artificial setting than the present one in which to evaluate tolerance [29]. Corticosteroids are also a routine part of the management of acute asthma and, apart from their anti-inflammatory actions, have been shown to upregulate $\beta_{2}$ receptors [1]. They were not administered in this study model. It has been reported that $\beta$-adrenoceptor downregulation may be reversed with systemic corticosteroids [30]. However, JONES et al. [14] have shown that intravenous hydrocortisone does not reverse $\beta_{2}$-adrenoceptor downregulation within the first $2 \mathrm{~h}$ of administration and HANCOX et al. [12] demonstrated that long-term administration of inhaled steroid does not prevent the development of bronchodilator tolerance.

To conclude, it has been demonstrated that a significantly attenuated bronchodilator response to acutely administered $\beta$-agonist occurs in patients who are continuously exposed to inhaled $\beta$-agonist and that this effect increases linearly with increasing bronchoconstriction. This was evident in terms of the rate of response to bronchodilator as well as maximum bronchodilatation achieved. There was striking variability between patients in these outcomes. The present results may help to explain the clinical observation that the response to $\beta$-agonist during acute severe asthma is variable and often poor.

Acknowledgements. The authors would like to thank GlaxoSmithKline (New Zealand) for the supplies of salbutamol.

\section{References}

1. Barnes PJ. Beta-adrenergic receptors and their regulation. Am J Respir Crit Care Med 1995; 152: 838-860.
2. Cockcroft DW, Swystun VA. Functional antagonism: tolerance produced by inhaled beta 2 agonists. Thorax 1996; 51: 1051-1056.

3. O'Connor BJ, Aikman SL, Barnes PJ. Tolerance to the nonbronchodilator effects of inhaled beta 2-agonists in asthma. N Engl J Med 1992; 327: 1204-1208.

4. Newnham DM, McDevitt DG, Lipworth BJ. Bronchodilator subsensitivity after chronic dosing with eformoterol in patients with asthma. Am J Med 1994; 97: 29-37.

5. Newnham DM, Grove A, McDevitt DG, Lipworth BJ. Subsensitivity of bronchodilator and systemic beta 2 adrenoceptor responses after regular twice daily treatment with eformoterol dry powder in asthmatic patients. Thorax 1995; 50: 497-504.

6. Nelson HS, Raine D Jr, Doner HC, Posey WC. Subsensitivity to the bronchodilator action of albuterol produced by chronic administration. Am Rev Respir Dis 1977; 116: 871878.

7. Grove A, Lipworth BJ. Bronchodilator subsensitivity to salbutamol after twice daily salmeterol in asthmatic patients. Lancet 1995; 346: 201-206.

8. Larsson S, Svedmyr N, Thiringer G. Lack of bronchial beta adrenoceptor resistance in asthmatics during long-term treatment with terbutaline. J Allergy Clin Immunol 1977; 59: 93-100.

9. Lipworth BJ, Struthers AD, McDevitt DG. Tachyphylaxis to systemic but not to airway responses during prolonged therapy with high dose inhaled salbutamol in asthmatics. Am Rev Respir Dis 1989; 140: 586-592.

10. Schuster A, Kozlik R, Reinhardt D. Influence of short- and long-term inhalation of salbutamol on lung function and beta 2-adrenoceptors of mononuclear blood cells in asthmatic children. Eur J Pediatr 1991; 150: 209-213.

11. Ullman A, Hedner J, Svedmyr N. Inhaled salmeterol and salbutamol in asthmatic patients. An evaluation of asthma symptoms and the possible development of tachyphylaxis. Am Rev Respir Dis 1990; 142: 571-575.

12. Hancox RJ, Aldridge RE, Cowan JO, et al. Tolerance to beta-agonists during acute bronchoconstriction. Eur Respir J 1999; 14: 283-287.

13. van der Woude HJ, Winter TH, Aalbers R. Decreased bronchodilating effect of salbutamol in relieving methacholine induced moderate to severe bronchoconstriction during high dose treatment with long acting beta2 agonists. Thorax 2001; 56: 529-535.

14. Jones SL, Cowan JO, Flannery EM, Hancox RJ, Herbison GP, Taylor DR. Reversing acute bronchoconstriction in asthma: the effect of bronchodilator tolerance after treatment with formoterol. Eur Respir J 2001; 17: 368-373.

15. Standards for the diagnosis and care of patients with chronic obstructive pulmonary disease (COPD) and asthma. This official statement of the American Thoracic Society was adopted by the ATS Board of Directors, November 1986. Am Rev Respir Dis 1987; 136: 225-244.

16. Yan K, Salome C, Woolcock AJ. Rapid method for measurement of bronchial responsiveness. Thorax 1983; 38: $760-765$.

17. Mak JC, Rousell J, Haddad EB, Barnes PJ. Transforming growth factor-beta1 inhibits beta2-adrenoceptor gene transcription. Naunyn Schmiedebergs Arch Pharmacol 2000; 362 : 520-525.

18. Rodrigo G, Rodrigo C, Burschtin O. A meta-analysis of the effects of ipratropium bromide in adults with acute asthma. Am J Med 1999; 107: 363-370.

19. Rodrigo GJ, Rodrigo C. First-line therapy for adult patients with acute asthma receiving a multiple-dose protocol of ipratropium bromide plus albuterol in the emergency department. Am J Respir Crit Care Med 2000; 161: 1862-1868.

20. Stoodley RG, Aaron SD, Dales RE. The role of ipratropium bromide in the emergency management of acute asthma exacerbation: a metaanalysis of randomized clinical trials. Ann Emerg Med 1999; 34: 8-18. 
21. Van Metre TE Jr. Adverse effects of inhalation of excessive amounts of nebulized isoproterenol in status asthmaticus. J Allergy 1969; 43: 101-113.

22. Pansegrouw DF, Weich DJ, le Roux FP. Beta-adrenergic receptor tachyphylaxis in acute severe asthma. A preliminary communication. S Afr Med J 1991; 80: 229-230.

23. Korosec M, Novak RD, Myers E, Skowronski M, McFadden ER Jr. Salmeterol does not compromise the bronchodilator response to albuterol during acute episodes of asthma. Am J Med 1999; 107: 209-213.

24. Drazen JM, Israel E, Boushey HA, et al. Comparison of regularly scheduled with as-needed use of albuterol in mild asthma. Asthma Clinical Research Network. N Engl J Med 1996; 335: 841-847.

25. Wahedna I, Wong CS, Wisniewski AF, Pavord ID, Tattersfield AE. Asthma control during and after cessation of regular beta 2-agonist treatment. Am Rev Respir Dis 1993; 148: 707-712.

26. Cloosterman SG, Bijl-Hofland ID, van Herwaarden CL, et al. A placebo-controlled clinical trial of regular monotherapy with short-acting and long-acting beta(2)-agonists in allergic asthmatic patients. Chest 2001; 119: 1306-1315.

27. Rhoden KJ, Meldrum LA, Barnes PJ. Inhibition of cholinergic neurotransmission in human airways by beta 2-adrenoceptors. J Appl Physiol 1988; 65: 700-705.

28. Bai TR, Lam R, Prasad FY. Effects of adrenergic agonists and adenosine on cholinergic neurotransmission in human tracheal smooth muscle. Pulm Pharmacol 1989; 1: 193-199.

29. Hancox RJ, Subbarao P, Kamada D, Watson RM, Hargreave FE, Inman MD. Beta2-agonist tolerance and exercise-induced bronchospasm. Am J Respir Crit Care Med 2002; 165: 10681070.

30. Tan KS, Grove A, McLean A, Gnosspelius Y, Hall IP, Lipworth BJ. Systemic corticosteriod rapidly reverses bronchodilator subsensitivity induced by formoterol in asthmatic patients. Am J Respir Crit Care Med 1997; 156: $28-35$. 